tình trạng viêm mạn tính và suy dinh dương là những yếu tố quan trọng làm suy giảm khả năng miễn dịch. Mối quan hề chặt chẽ giữa suy dinh dưỡng, viêm nhiễm và xơ vữa đông mach ở bênh nhân lọc máu cho thấy sự hiện diện của hội chứng suy dinh dưỡng, viêm và xơ vữa động mạch, có liên quan đến tỳ lệ tử vong cao. Giảm albumin máu vấn là dấu hiệu lâm sàng tốt nhất của suy dinh dưỡng nhưng sự hiện diện của tình trạng viêm nhiễm có thể là một yếu tố tiên lượng mạnh mẽ hơn cho các rối loạn dạ dày ruột cũng như nguy cơ tử vong [8].

\section{KẾT LUÂ̂N}

- Điểm GSRS trung bình là $8(2,25$ - 13), có $80 \%$ bệnh nhân xuất hiện ít nhất 01 triệu chứng dạ dày ruột.

- Nhóm bênh nhân tuổi $\geq 60$; lọc máu $\geq 10$ năm có chỉ số GSRS trung bình cao hơn nhóm không có đặc điểm trên, $p<0,01$. Có mối tương quan nghịch điểm GSRS với nồng độ hemoglobin và albumin máu, $\mathrm{p}<0,01$.

\section{TÀI LIẸU THAM KHẢO}

1. Usta M, Ersoy A, Ayar $Y$, et al. (2020). Comparison of endoscopic and pathological findings of the upper gastrointestinal tract in transplantcandidate

patients undergoinghemodialysis or peritoneal dialysis treatment: a review of literature. BMC Nephrol. 21(1):444.

2. Dong R., Guo ZY, Ding JR, et al. (2014). Gastrointestinal symptoms: a comparison between patients undergoing peritoneal dialysis and hemodialysis. World ] Gastroenterol. 20(32): 11370-5.

3. Esteve Simo V, Moreno-Guzmán $F$, Martínez Calvo G, et al. (2015). Administration of calcimimetics after dialysis: same effectiveness, better gastrointestinal tolerability.Nefrologia. 35(4):403-9.

4. Daniels G, Robinson JR, Walker $C$, et al. (2015). Gastrointestinal symptoms among African Americans undergoing hemodialysis. Nephrol. Nurs. J. 42 : 539-49.

5. Mitrovic M, Majster Z. (2015). The prevalence, severity and diversity of gastrointestinal symptoms in hemodialysis and peritoneal dialysis patients. Nephrol. Dial. Transplant. 30: SP706.

6. Lê Xuân Bách, Lê Việt Thắng, Hoàng Cao Sạ (2015). Khảo sát đắc đđiểm rối loạn tiêu hoá bằng thang điểm đánh giá tỷ lệ triêu chứng da dày ruột ở bệnh nhân suy thận mạn tính giai đoạn III-IV̀. Tap chí Y Dược hoc Quân sứ, số 40: 43-48.

7. Zuvela J, Trimingham C, Leu RL, et al. (2018). Gastrointestinal symptoms in patients receiving dialysis: A systematic review. Nephrology 23: 718-727.

8. Carrera-Jiménez $D$, Miranda-Alatriste $P$, Atilano-Carsi $X$, et al. (2018). Relationship between Nutritional Status and Gastrointestinal Symptomsin Geriatric Patients with EndStage Renal Disease on Dialysis. Nutrients. 10(4):425.

\title{
MỐI TƯƠNG QUAN GIỮA CÁC CHỈ SỐ NHÂN TRẮC VÙNG XƯƠNG MŨI TRÊN THI THỂ NGƯỜI VIẸTT TRƯỞNG THÀNH
}

\author{
Hồ Nguyễn Anh Tuấn*, Võ Văn Hải**, \\ Cao Nguyễn Hoài Thương*, Phạm Đăng Diệu*
}

\section{TÓM TẮT}

Muc tiêu: Xác định kích thước trung bình của các chỉ số nhân trắc trên xương mũi và mối tương quan giữa các kích thước này với nhau. Phương pháp: Nghiên cứu cắt ngang khảo sát xương mũi từ xác ướp formalin $10 \%$ của người Viêtt trưởng thành, tai bộ môn Giải phẫu Trường Đại học y khoa Phạm Ngọc Thạch từ tháng 05/2019 đến tháng 01/2021. Sử dụng phương pháp đo trực tiếp các chỉ số nhân trắc trên xương mũi, các chỉ số sẽ được đo 2 lần và lấy kết quả trung bình giữ̃̃a 2 lần đo. Kết quả: Nghiên cứu khảo sát được 33 mẫu xương mũi, với 45,5\% là nữ, độ tuổi dao động từ $20-87$ tuổi, với tuổi trung bình là 65 tuổi.Các kích

*Trường Đại học Y khoa Phạm Ngọc Thạch

**Đai hoc Y Dước TP Hồ Chí Minh

Chiu trcachs nhiệm chính: Hồ Nguyễn Anh Tuấn

Email: hnat503@pnt.edu.vn

Ngày nhận bài: 26/3/2021

Ngày phản biên khoa học: 10/5/2021

Ngày duyệt bài: 22/5/2021 thước nhân trắc của xương mũi đo được như sau: chiều rộng xương mũi trên là $10,21 \pm 2,53 \mathrm{~mm}$; chiều rộng xương mũi dưới là $17,08 \pm 2,08 \mathrm{~mm}$; đoạn hẹp nhất của xương mũi có kích thước trung bình là $8,24 \pm$ $1,58 \mathrm{~mm}$. Đoan hẹp nhất của xương mũi đa số nằm trên khóe mắt trong và nằm ngang hoăc dưới điểm $S$. Chiều dài xương mũi $(N-R)$ trung bình là $23,81 \pm$ $2,94 \mathrm{~mm}$. Nghiên cứu tìm thây mối tương quan giữa độ rộng xương mũi trên với đoạn hẹp nhất của xương mũivà mối tương quan giữa khoảng cách từ điểm $\mathrm{N}$ đến điểm $S$ với khoảng cách từ điểm $S$ đến điểm $R$. Kết luân: Khi tiến hànhphâ̂u thuật thẩm mỹ mũicần cân nhẳc đến mối tương quan giữa các kích thước xương mũi, nhằm tao đước môt chiếc mũi cân đối, tự nhiên, giảm thiểu biến chứng phẫu thuật và nâng cao sự hài lòng của bênh nhân.

Tư khóa: Nhân trắc mũi, kích thước xương mũi, phẫu thuật tạo hình mũi, nasion, sellion, rhinion

\section{SUMMARY \\ THE CORRELATION BETWEEN THE ANTHROPOMETRIC INDICATORS OF THE}


NASAL BONE OF THE VIETNAMESE CADAVERS

Objectives: To determine the averaged anthropometric indicators of the nasal bone and their correlation. Methods: Cross-sectional descriptive studies on the nasal bones from dried Vietnameses corpses at the Anatomy Department of Pham Ngoc Thach University of Medicine from May 2019 to January 2021. By the directly measurement of anthropometric indicators on the nasal bone, these indexes will be measured twice and record the averaged results. Results: There are 33 nasal bones, with $45.5 \%$ female, the age range from 20 to 87 years old, the average age is 65 years. The sizes of the nasal bone were measured as follows: the upper width of the nasal bone is $10.212 .53 \mathrm{~mm}$; the lower width of nasal bone is $17.08 \pm 2.08 \mathrm{~mm}$; the narrowest is 8.24 $\pm 1.58 \mathrm{~mm}$. The narrowest segment of nasal bone is above the eye and equal to or below the Sellion. The average length of the nasal bone $(\mathrm{N}-\mathrm{R})$ is $23.81 \pm$ $2.94 \mathrm{~mm}$. There are the correlation between the upper width with the narrowest segment of the nasal bone; the correlation between the distance from Nasion to Sellion and the distance from Sellion to Rhinion. Conclusion: In rhinoplasty, it is necessary to consider the correlation between the anthropometric indicators of the nasal bones, so that it leads to the beautiful results, prevents the surgical complications and enhances the patient's satisfication.

Key words: Nasal anthropometry, nasal bone, nasion, rhinoplasty, sellion, rhinion.

\section{I. ĐĂT VẤN ĐỀ}

Vẻ đẹp khuôn mặt là kết quả của sự hài hòa giữa các cấu trúc thể hiện trên khuôn mặt, mà trong đó mũi, với vị trí trung tâm, được cho là phần quan trọng và ấn tượng nhất. Hiện nay, phẫu thuật thẩm mỹ mũi ngày càng trở nên phổ biến ở các nước Châu Á với mục đích là tạo được một chiếc mũi cân đối và tự nhiên ${ }^{(1)}$. Để làm được điều này thì việc hiểu rõ về cấu trúc giải phẩu của xương mũi là điều cần thiết.

Về cấu tạo thì xương mũi gồm hai xương nhỏ hình chữ nhật, nằm ngay đường giữa mặt, tiếp giáp với xướng trán ở phía trên và với xương hàm trên ở phía dưới, tạo thành một khối hài hòa trên khuôn mặt(2). Các nhà nghiển cứu cho rằng có sự khác biệt đặc trưng giữa các chủng tộc về chiều dài, chiều rộng, vị trí và độ cong của xương mũi và cũng chính những điều này đã ảnh hưởng đến nét thẩm mỹ trên khuôn mặt mỗi người (3). Việc can thiệp thay đổi các chỉ số này khi chưa hiểu rõ mối liên quan của chúngcó thể gây cản trở kết quả nâng mũi, dẫn đến kết quả thẩm mỹ kém và biến chứng sau phẫu thuật.

Tuy nhiên, đến thời điểm hiện tại, thậm chí trên thế giới cũng có rất ít các nghiên cứu về chủ đề này. Tại Việt Nam, theo sự hiểu biết của chúng tôi, chưa có nghiên cứu nào hoàn toàn tập trung nghiên cứu về hình thái và kích thước xương mũi người Việt. Vì vậy, chúng tôi thực hiện nghiên cứu này với mục tiêu xác định kích thước trung bình của các chỉ số nhân trắc trên xương mũi và mối tương quan giữa các kích thước này với nhau.

\section{II. ĐỐI TƯỢNG VÀ PHƯƠNG PHÁP NGHIÊN CỨU}

2.1. Thiết kế nghiên cứu: nghiên cứu cắt ngang.

2.2. Đối tượng nghiên cứu: xương mũi từ xác ướp formalin $10 \%$ của người Việt trưởng thành, tại bộ môn Giải phẫu Trường Đại học y khoa Pham Ngoc Thach.

2.3. Thời gian nghiên cứu: từ tháng 5/2020 - tháng 12/2020.

2.4. Cỡ mấu: Sử dụng công thức tính cõ̃ mẫu ước lượng một số trung bình, với $a=0,05 \rightarrow Z_{(1-}$ a/2) = 1,96; d = 1mm; chọn $\sigma=2,6 \mathrm{~mm}$ (độ lệch chuẩn của chiều rộng xương mũi trên và xương mũi dưới trong nghiên cứu của tác giả Hwang T.S) ${ }^{(2)} \rightarrow$ cần khảo sát ít nhất là 26 xương mũi.

Thực tế nghiên cứu khảo sát được 33 mẫu xương mũi.

2.5. Kỹ thuật chơn mẫu: Nghiên cứu sử dụng kỹ thuật chọn mẩu thuận tiện trên các xác ướp formalin $10 \%$ của người Việt trưởng thành, tại trường Đại học Y khoa Phạm Ngọc Thạch và̀o thời điểm nghiên cứu theo tiểu chuẩn chọn mẫu cho đến khi đủ mẫu.

\subsection{Tiêu chuẩn chọn mẫu}

Tiêu chuẩn chọn vào: Xác người Việt trưởng thành trên 18 tuổi, còn nguyên vẹn vùng tháp mũi và chưa phẫu thuật trên vùng mũi.

Tiêu chuẩn loại ra: Xác biến dạng tháp mũi, u bướu hay bất thưường ở vùng mặt.

\subsection{Phương pháp và công cụ thu thập} số liệu

Cồng cụ thu thập: - Bộ dụng cụ phẫu tích

- Thước kẹp caliper của hãng Vogel (Đức), với sai số $0,01 \mathrm{~mm}$

\section{Phương pháp thu thâp}

- Bước 1: Vẽ và rạch da dọc theo bờ tự do lỗ mũi trước 2 bên nối với nhau hình chữ $V$ ngược ở ngay dưới cột trụ mũi, rạch dọc theo giữa sống mũi đến đỉnh mũi, toàn bô vạt da sẽ được lật sang 2 bên để bộc lộ toàn bộ mô dưới da, khung xương sụn của tháp mũi.

- Bước 2: Bóc tách toàn bộ các lớp SMAS, mõ, dây chằng và sụn tháp mũi, màng sụn, màng xương.

- Bước 3: Tiến hành đo các kích thước của xương mũi

Các biến số cân thu thâp. Nghiên cứu tiến hành đotrực tiếp (đo 2 lần và lấy trung bình của 
2 lần đo)các kích thước chiều ngang và chiều dọc của xương mũi như sau:

- Kích thước chiều ngang bao gồm: độ rộng xương mũi tại các điểm: điểm giữa khớp mũi trán ( $\mathrm{N}$ : nasion), điểm thấp nhất của xương mũi(S: sellion), điểm giữa khớp xương sụn (R: rhinion); chiêu rộng xương mũi trên, chiều rộng xương mũi dưới, khoảng cách hẹp nhất của xương mũi.

- Kích thước chiều dọc bao gồm: khoảng cách từ điểm $N$ đến $S, N$ đến $R, S$ đến điểm gù xương ( $K$ : kyphion), $K$ đến $R$ và $S$ đến $R$.

2.8. Phương pháp xử lý và phân tích số liệu. Số liệu được mô tả dưới dạng tần số và tî lệ \% với các biến định tính; trung bình và độ lểch chuẩn với các biến đinh lượng. Sử dung kiểm định T-test để xác định sự khác biệt về các kích thước xương theo giới và điểm gù xương. Mối liên quan giữa các kích thước xương mũi được xác định bằng hệ số tương quan ( $r$ ) và xây dựng phương trình hồi quy tuyến tính.

2.9. Đạo đức trong nghiên cứu. Nghiên cứu đã được chấp thuận của Hội đồng đạo đức trong nghiên cứu y sinh học Trường Đại học $\mathrm{Y}$ khoa Phạm Ngọc Thạch theo Quyết định sô 66/HĐĐĐ ngày 10/05/2019.

\section{KẾT QUẢ NGHIÊN CỨU}

Khảo sát được 33 mẫu xương mũi, trong đó có 31 xác khô và 2 xác tươii. Tỉ lệ nữ là $45,5 \%$, độ tuổi dao động từ 20 - 87 tuổi, với tuổi trung bình là 65 tuổi. Tỉ lệ xương mũi có điểm gù xương (điểm $\mathrm{K}$ ) là $24,2 \%$ với đa số điểm $\mathrm{K}$ nằm ở chính giữa xương (chiếm 75\%).

\subsection{Các kích thước chiêu ngang của xương mũi}

Bảng 1. Các kích thước chiều ngang của xương mũi theo giới $(n=33)$

\begin{tabular}{|c|c|c|c|c|}
\hline & \multicolumn{3}{|c|}{ Giới } & \multirow{2}{*}{ Giá trị $\mathbf{p}^{*}$} \\
\hline & Chung & $\operatorname{Nam}(n=18)$ & Nữ $(n=15)$ & \\
\hline Khoảng rộng xương tại N: Trái & $5,52 \pm 1,34$ & $5,53 \pm 1,39$ & $5,51 \pm 1,32$ & 0,953 \\
\hline Phải & $5,59 \pm 1,31$ & $5,72 \pm 1,51$ & $5,43 \pm 1,05$ & 0,527 \\
\hline Khoảng rộng xương tại S: Trái & $5,05 \pm 0,84$ & $4,99 \pm 0,97$ & $5,13 \pm 0,69$ & 0,651 \\
\hline Phải & $5,17 \pm 0,95$ & $5,27 \pm 1,05$ & $5,04 \pm 0,83$ & 0,492 \\
\hline Khoảngrộng xương tại R: Trái & $9,93 \pm 1,49$ & $10,42 \pm 1,56$ & $9,34 \pm 1,21$ & 0,036 \\
\hline Phải & $11,18 \pm 2,15$ & $11,59 \pm 2,28$ & $10,68 \pm 1,94$ & 0,232 \\
\hline Chiều rộng Xương mũi trên & $10,21 \pm 2,53$ & $10,54 \pm 2,83$ & $9,81 \pm 2,14$ & 0,419 \\
\hline Chiều rộng xương mũi dưới & $17,08 \pm 2,08$ & $17,55 \pm 1,96$ & $16,53 \pm 2,14$ & 0,163 \\
\hline Đoạn hẹp nhất của xương mũi & $8,24 \pm 1,58$ & $8,23 \pm 1,71$ & $8,26 \pm 1,47$ & 0,952 \\
\hline \multicolumn{5}{|c|}{ Khoảng cách từ đoạn hẹp nhất - khóe măt trong } \\
\hline Ngang $(n=8)$ & $9,32 \pm 1,19$ & $9,20 \pm 0,90$ & $9,39 \pm 0,50$ & 0,850 \\
\hline Trên $(n=25)$ & $7,90 \pm 1,55$ & $8,03 \pm 0,44$ & $7,70 \pm 0,42$ & 0,609 \\
\hline \multicolumn{5}{|c|}{ Khoảng cách từ đoạn hẹp nhất - điếm S } \\
\hline Ngang $(\dot{n}=11)$ & $8,60 \pm 1,51$ & $9,59 \pm 0,41$ & $7,78 \pm 0,59$ & 0,040 \\
\hline Trên $(n=3)$ & $5,46 \pm 0,43$ & $5,46 \pm 0,43$ & // & // \\
\hline Dưới $(n=19)$ & $8,47 \pm 1,31$ & $8,38 \pm 0,39$ & $8,58 \pm 0,49$ & 0,747 \\
\hline
\end{tabular}

$(*)$ : Kiểm định T-test

Về các kích thước chiều ngang của xương mũi, nhìn chung xương mũi tại $S$ có khoảng rộng nhỏ nhất (khoảng $5-6 \mathrm{~mm}$ ) ở mỗi bên. Đoạn hẹp nhất của xương mũi có chiều ngang trung bình là $8,24 \mathrm{~mm}$. Đa số không có sự khác biệt về chiều rộng xương mũi ở 2 giới.

Chủ yếu xương mũi người Việt có đoạn hẹp nhất của xương nằm trên dây chằng khóe mắt trong (75,8\%) và dưới điểm $S(57,6 \%)$.

Bảng 2. Các kích thước chiều ngang của xương mũi theo điểm gù xương $(n=33)$

\begin{tabular}{|c|c|c|c|}
\hline \multirow{2}{*}{} & \multicolumn{2}{|c|}{ Điếm K } & \multirow{2}{*}{ Giá trị p* } \\
\cline { 2 - 3 } & Có $\mathbf{~} \mathbf{n}=\mathbf{8})$ & Không $(\mathbf{n}=\mathbf{2 5})$ & 0,168 \\
\hline Khoảng rộng xương tại N: Trái & $6,09 \pm 1,30$ & $5,34 \pm 1,32$ & 0,628 \\
\hline Phải & $5,79 \pm 0,76$ & $5,52 \pm 1,45$ & 0,802 \\
\hline Khoảng rộng xương tại S: Trái & $4,99 \pm 0,65$ & $5,07 \pm 0,91$ & 0,267 \\
\hline Phải & $4,84 \pm 0,95$ & $5,27 \pm 0,94$ & 0,407 \\
\hline Khoảng rộng xương tại R: Trái & $10,46 \pm 2,15$ & $9,76 \pm 1,23$ & 0,839 \\
\hline Phải & $11,32 \pm 1,57$ & $11,13 \pm 2,33$ & 0,241 \\
\hline Chiều rộng xương mũi trên & $11,14 \pm 1,75$ & $9,92 \pm 2,70$ & 0,161 \\
\hline Chiếu rộng xương mữi dưới & $16,18 \pm 1,39$ & $17,37 \pm 2,20$ & 0 \\
\hline
\end{tabular}




\begin{tabular}{|c|c|c|c|}
\hline Đoạn hẹp nhất của xương mũi & $8,10 \pm 1,26$ & $8,29 \pm 1,69$ & 0,774 \\
\hline \multicolumn{4}{|c|}{ Khoảng cách từ đoạn hẹp nhất - khóe mắt trong } \\
\hline Ngang $(n=8)$ & 7,8 & $9,53 \pm 0,42$ & // \\
\hline Trên $(n=25)$ & $8,14 \pm 0,51$ & $7,81 \pm 039$ & 0,636 \\
\hline \multicolumn{4}{|c|}{ Khoảng cách từ đoạn hẹp nhất - điếm S } \\
\hline Ngang $(n=11)$ & $8,73 \pm 0,84$ & $8,56 \pm 0,57$ & 0,881 \\
\hline Trên $(n=3)$ & $1 /$ & $5,46 \pm 0,43$ & // \\
\hline Dưới $(n=19)$ & $7,73 \pm 0,50$ & $8,74 \pm 0,35$ & 0,142 \\
\hline
\end{tabular}

$(*)$ : Kiểm đinh T-test

Nghiên cứu chưa tìm thấy sự khác biệt về các kích thước chiều ngang của xương mũi theo điểm gù xương. Tuy nhiên, theo như kết quả nghiên cứu có thể thấy ở những xương mũi có điểm gù thì đa số đoạn hẹp nhất của xương sẽ ở trên dây chằng khóe mắt trong và ở ngang hoặc dưới điểm $\mathrm{S}$.

\subsection{Các kích thước chiêu dọc của xương mũi}

Bảng 3. Các kích thước chiều dọc của xương mũi theo giới $(n=33)$

\begin{tabular}{|c|c|c|c|c|}
\hline & \multicolumn{3}{|c|}{ Giới } & \multirow{2}{*}{ Giá trị p* } \\
\cline { 2 - 4 } & Chung & Nam (n = 18) & Nũ̃ (n= 15) & \\
\hline $\mathbf{N}-\mathbf{S}$ & $5,71 \pm 1,22$ & $5,56 \pm 1,25$ & $5,89 \pm 1,19$ & 0,452 \\
\hline $\mathbf{S}-\mathbf{K}(\mathbf{n}=\mathbf{8})$ & $14,31 \pm 0,82$ & $14,54 \pm 0,73$ & $14,08 \pm 0,93$ & 0,461 \\
\hline $\mathbf{K}-\mathbf{R}(\mathbf{n}=\mathbf{8})$ & $4,56 \pm 1,10$ & $4,61 \pm 1,29$ & $4,52 \pm 1,08$ & 0,917 \\
\hline $\mathbf{S}-\mathbf{R}$ & $18,56 \pm 2,69$ & $18,85 \pm 3,02$ & $18,22 \pm 2,29$ & 0,515 \\
\hline $\mathbf{N}-\mathbf{R}$ & $23,81 \pm 2,94$ & $23,79 \pm 3,46$ & $23,83 \pm 2,29$ & 0,971 \\
\hline
\end{tabular}

(*): Kiểm định T-test

Chiều dài xương mũi người Việt $(\mathrm{N}-\mathrm{R})$ trung bình khoảng 23,81mm, trong đó khoảng cách từ điểm $\mathrm{N}$ đến $\mathrm{S}$ trung bình là $5,71 \mathrm{~mm}$. Nhìn chung, điểm gù xương nằm khá gần điểm $R$ (khoảng cách trung bình từ $K-R$ là 4,56mm).

Nghiên cứu chưa tìm thấy sự khác biệt về các kích thước chiều dọc của xương ở 2 giới.

Bảng 4. Các kích thước chiều dọc của xương mũi theo điêm gù xương $(n=33)$

\begin{tabular}{|c|c|c|c|}
\hline & \multicolumn{2}{|c|}{ Điểm K } & \multirow{2}{*}{ Giá trị } \\
\cline { 2 - 4 } & Có $\mathbf{( n = 8 )}$ & $\begin{array}{c}\text { Không (n } \\
\mathbf{2 5})\end{array}$ & \\
\hline $\mathbf{N}-\mathbf{S}$ & $5,19 \pm 0,97$ & $5,88 \pm 1,26$ & 0,169 \\
\hline $\mathbf{S}-\mathbf{R}$ & $18,87 \pm 1,38$ & $18,46 \pm 3,01$ & 0,601 \\
\hline $\mathbf{N}-\mathbf{R}$ & $23,91 \pm 1,76$ & $23,77 \pm 3,26$ & 0,910 \\
\hline
\end{tabular}

(*): Kiểm định T-test

Khi phân tích các kích thước chiều dọc của xương mũi, nghiên cứu chưa tìm thây sự khác biệt về các kích thước này theo điểm gù xương.

Mối liên quan giữa các kích thước xương mũi

Bảng 5. Mối liên quan giữa kích thước đoạn $N-S$ và đoạn $S-R$

\begin{tabular}{|c|c|c|}
\hline $\mathbf{N}-\mathbf{S}$ & Hệ số tương quan(r) & Giá trị $\mathbf{~}$ \\
\hline $\mathrm{S}-\mathrm{R}$ & $-0,374$ & 0,032 \\
\hline \multicolumn{3}{|c|}{ Phương trình hồi quy } \\
\hline $\begin{array}{c}\text { Hệ số phương } \\
\text { trình }\end{array}$ & $-0,17$ & 0,032 \\
\hline Hằng số & 8,85 & $<0,001$ \\
\hline
\end{tabular}

Nghiên cứu tìm thấy mối tương quan nghich và trung bình giữa khoảng cách từ điểm $\mathrm{N}$ đến điểm $S$ và từ điểm $S$ đến điểm $R$. Từ đó, chúng tôi xây dựng được phương trình hồi quy như sau:

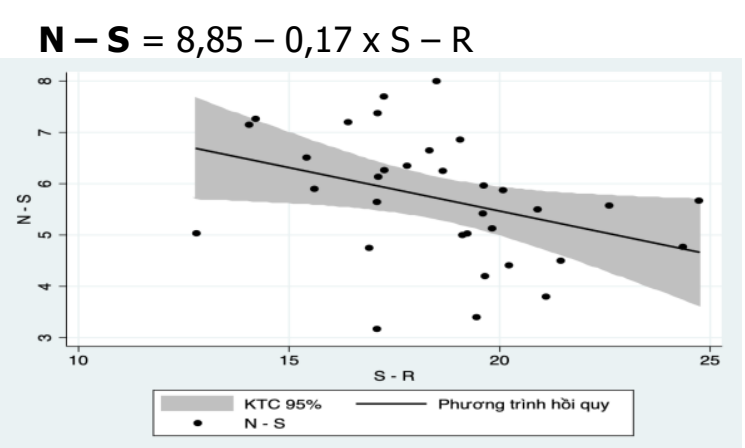

Hình 1. Mối tương quan giữa kích thước đoạn $N$ $-S$ và $S-R$

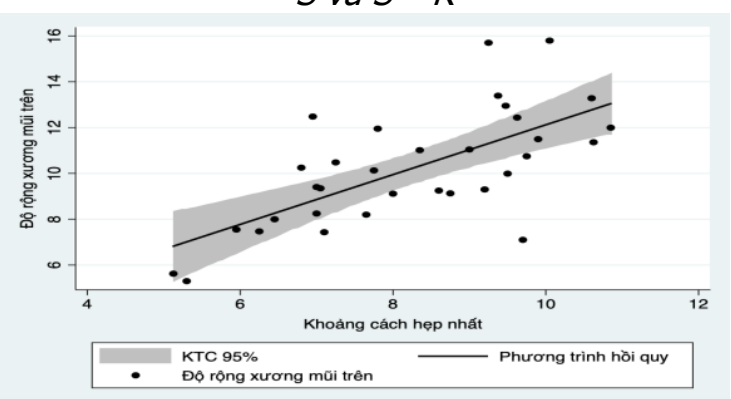

Hình 2. Mối tương quan giữa chiều rộng xương mũi trên và khoảng cách đoạn hẹp nhất

Bảng 6. Liên quan giữa độ rộng xương mũi trên và khoảng cách hẹp nhất của xương mũi

\begin{tabular}{|c|c|c|}
\hline $\begin{array}{c}\text { Chiêu rộng xương } \\
\text { mữi trên }\end{array}$ & $\begin{array}{c}\text { Hệ số tương } \\
\text { quan (r) }\end{array}$ & Giá trị p \\
\hline Khoảng cách hẹp nhất & 0,678 & $<0,001$ \\
\hline \multicolumn{3}{|c|}{ Phương trình hồi quy } \\
\hline Hệ số phương trình & 0,05 & $<0,001$ \\
\hline Hằng số & 1,58 & $<0,001$ \\
\hline
\end{tabular}


Nghiên cứu tìm thấy mối tương quan thuận và mạnh giữa chiều rộng xương mũi trên và khoảng cách đoạn hẹp nhất của xương mũi. Từ đó, chúng tôi xầy dựng được phương trình hồi quy như sau: Chiêu rộng xương mũi trên $=1,58$ + 0,05 x Khoảng cách hẹp nhất.

\section{BÀN LUẬN}

4.1. Kích thước chiêu ngang của xương mũi. Trong nghiên cứu này, chúng tôi thực hiện đo các kích thước trên xương mũi một cách chi tiết ở từng vị trí. Tại điểm giữa khớp mũi trán $(\mathrm{N})$, khoảng rộng xương ở 2 bên trái phải lần lượt là $5,52 \pm 1,34 \mathrm{~mm}$ và $5,59 \pm 1,31 \mathrm{~mm}$. Tương tự, chúng tôi cũng đo khoảng rộng xương trái phải tại điểm thấp nhất của xương mũi (S) và điểm khớp xương sụn (R). Trong đó, kích thước nhỏ nhất là

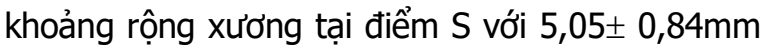
ở bên trái và $5,17 \pm 0,95 \mathrm{~mm}$ ở bên phải.

Chiều rộng xương mũi trên trung bình là $10,21 \pm 2,53 \mathrm{~mm}$; chiều rộng xương mũi dưới là $17,08 \pm 2,08 \mathrm{~mm}$. Đoạn hep nhất của xương mũi có chiều ngang trung bình là $8,24 \pm 1,58 \mathrm{~mm}$. Nhìn chung, các kích thước này không có sự khác biệt theo giới tính, độ tuổi và có hay không có điểm gù xương.

Tại Việt Nam, trong các nghiên cứu trước đây, có tác giả Trân Thị Anh Tú có từng khảo sát kích thước xương mũi trên 30 mẫu xương ${ }^{(4)}$. Tuy nhiên, trong nghiên cứu này, tác giả chỉ khảo sát vài chỉ số và không đề cập đến các kích thước chiều ngang như trong nghiên cứu của chúng tôi.

Khi so sánh với các nghiên cứu trên thễ giới, chúng tôi có bảng kết quả như sau:

\begin{tabular}{|c|c|c|c|c|c|}
\hline \multirow{2}{*}{ Nghiên cứu } & \multirow{2}{*}{ Chủng tộc } & \multicolumn{2}{|c|}{ Chiêu rộng xương mũi trên } & \multicolumn{2}{|c|}{ Chiêu rộng xương mũi dưới } \\
\hline & & Nam & Nữ & Nam & Nữ \\
\hline Lang ${ }^{(5)}$ & Đức & \multicolumn{2}{|c|}{$13,0 \pm 2,4$} & \multicolumn{2}{|c|}{$16,3 \pm 2,5$} \\
\hline Hwang (2) & Hàn Quốc & $9,2 \pm 2,4$ & $8,8 \pm 2,6$ & $16,8 \pm 2,6$ & $17,0 \pm 2,0$ \\
\hline Richard(6) $^{(6)}$ & Mỹ & \multicolumn{2}{|c|}{$14 \mathrm{~mm}$} & \multicolumn{2}{|c|}{$\pi /$} \\
\hline Chúng tôi & Viêt & $10,54 \pm 2,83$ & $9,81 \pm 2,14$ & $17,55 \pm 1,96$ & $16,53 \pm 2,14$ \\
\hline
\end{tabular}

Theo như bảng so sánh trên, chiều rộng xương mũi trên giữa các chủng tộc không giống nhau, trong đó người Châu Âu và̀ người Mỹ lớn hơn người Châu Á, trong khi về chiều rộng xương mũi dưới lại không có nhiều khác biệt. Từ đây có thể gợi ý rằngcó thể do xuất phát từ đặc điểm có xương mũi trên rộng làm cho người Châu Á có đặc trưng mũi to bè, gốc mũi thấp, gây ảnh hưởng đến thẩm mỹ mũi.

Trong nghiên cứu chúng tôi còn thấy rằng chủ yếu xương mũi người Việt có đoạn hẹp nhất của xương nằm trên dây chẳng khóe mắt trong $(75,8 \%)$ và dưới điểm $S(57,6 \%)$. Tuy nhiên đặc điểm này xét ở các chủng tộc là hoàn toàn khác biệt. Tác giả Richard khi nghiên cứu trên người Mỹ cho rằng đoan hep nhất của xương mũi là ngay tại điểm thấp nhất của xương (điểm $S$ ) và kích thước trung bình của đoạn này khoảng $10 \mathrm{~mm}^{(6)}$. Và nghiên cứu vào năm 2015 của tác giả Lazovic, khảo sát 44 thi hài từ trường Đại học Y khoa Belgrade, Serbia cũng cho thây đoạn hẹp nhất của xương mũi là tại điểm $S$ và kích thước đoạn này là $12,13 \mathrm{~mm}{ }^{(7)}$.

Trong một nghiên cứu khác, tác giả Daniel và cộng sự có mô tả là khớp mũi trán nằm phía trên của dây chằng khóe mắt trong khoảng $5,8 \mathrm{~mm}$ và tỉ lệ có điểm gù xương mũi là $43 \%$. Một nghiên cứu của tác giả Palhazitrên 15 xác người da trắng còn có tî lệ có gù xương cao hơn với $67 \%$ (8). So sánh với nghiên cứu của chúng tôi thì tî lệ có điểm gù xương của người Việt lại thấp hơn nhiều. Như vậy, người da trắngcó tỉ lệ xương mũi có điểm gù cao hơn người Việt,điều này có thể xuất phát từ những khác biệt về mặt chủng tộc dẫn đến đặc điểm cấu trúc xương mũi hoàn toàn khác nhau.

4.2. Kích thước chiêu dọc của xương mũi. Chiều dài xương mũi người Việt $(N-R)$ trung bình khoảng 23,81 $\pm 2,94 \mathrm{~mm}$, trong đó khoảng cách từ khớp mũi trán đến điểm thấp nhất của xương trung bình là $5,71 \pm 1,22 \mathrm{~mm}$ và khoảng cách từ điểm thấp nhất đến điểm giữa khớp xương sụn là $18,56 \pm 2,69 \mathrm{~mm}$. Kết quả của chúng tôi hoàn toàn phù hợp với nghiên cứu trước đây như của tác giả Trần Thị Anh Tú về chiều dài của xương mũi(4).

Tác giả Lazovic cũng có mô tả đặc điểm và kích thước xương mũi từ 44 thi hài từ trường Đại học $Y$ khoa Belgrade, Serbia và cho thây rằng khoảng cách từ khớp mũi trán đến điểm thấp nhất của xương là $7,73 \mathrm{~mm}$ và khoảng cách từ điểm gù xương đến điểm giữa xương và sụn là $24,77 \mathrm{~mm}^{(7)}$. Nghiên cứu này đã cung cấp thêm những cơ sở cho thây đặc trưng về cấu trúc xương mũi ở các chủng tộc. Ta có thể thấy, ở người Serbia, điểm thấp nhất của xương nằm xa khớp mũi trán (khác người da trắng), đồng thời điểm gù xương nằm khá xa điểm giữa xương và sụn. Trong khi đó, ở người Việt chúng tôi nhận thấy điểm gù xương nằm khá gần điểm $\mathrm{R}$ với 
khoảng cách trung bình là 4,56 $1,10 \mathrm{~mm}$.

Mặc dù nghiên cứu này của chúng tôi tập trung vào giải phẫu học của xương mũi, nhưng từ đây có thể có một số ứng dụng về mặt lâm sàng. Ta có thể thấy những nhà phẫu thuật thẩm mỹ khi lên kế hoạch phẫu thuậtthường có xu hướng không phân biệt các chỉ số về kích thước nhân trắc trên da và trên xương. Viêc nhầm lẫn này có thể sẽ dẫn đến những can thiệp thiếu chính xác và mang lại những kết quả không mong muốn. Ngoài ra, việc tìm thây mối tương quan giữa các chỉ số này giúp cho nhà phẫu thuật khi can thiệp cần chú ý đến sự hài hòa giữa các cấu trúc của xương mũi.

\section{KẾT LUÂN}

Các nhà phẫu thuật thẩm mỹ mũi khi phẫu thuật cần cân nhắc đến mối tương quan giữa các kích thước xương mũi, nhằm tạo được một chiếc mũi cân đối, tự nhiên, giảm thiểu biến chứng phẫu thuật và nâng cao sự hài lòng của bệnh nhân.

Bên cạnh đó, cần có những nghiên cứu với cõ mẫu lớn và ứng dụng các kỹ thuật đo tiên tiến đối với các chỉ số không thể đo trực tiếp để làm phong phú thêm nguồn tài liệu tham khảo cho khoa học nhận dạng và pháp y.

TÀI LIỆU THAM KHẢO

1. Han K.H (1998) Rhinoplasty in Aesthetic Plastic Surgery, Koonja Publishing Inc,Seoul, Korea, p. 159.

2. Hwang T.S, Song J, Yoona $H$, et al (2005) "Morphometry of the nasal bones and piriform apertures in Koreans". Annals of Anatomy, 187, pp. 411-414.

3. Lee S.E., Yang T.Y, Han G.S, et al (2008) "Analysis of the nasal bone and nasal pyramid by three- dimensional computed tomography". Eur. Arch. Otorhinolaryngol, 265, pp. 421-424.

4. Trân Thị Anh Tú (2003) Hình thái, cấu trúc tháp mũi người trưởng thành, Luận án tiến sỹ y học, Đại học Y Dược TP Hồ Chí Minh, tr. 30-60.

5. Lang J, Baumeister R (1982) "Uber das postnatale Wachstum der Nasenhohle.". Gegenbaurs Morphol Jahrb, 128, pp. 354-393.

6. Richard Y.Ha, Ricardo A.M (2007) "Rhinoplasty". Selected Readings in Plastic Surgery, 10 (18), pp. 2-3.

7. Lazovic G.D, Daniel R.K, Janosevic L.B, et al (2015) "Rhinoplasty: The Nasal Bones - Anatomy and Analysis". Aesthetic Surgery Journal, 35 (3), pp. 255-263.

8. Palhazi P, Daniel R.K, Kosins A.M (2015) "The Osseocartilaginous Vault of the Nose: Anatomy and Surgical Observations". Aesthetic Surgery Journal, 35 (3), pp. 242-251.

\title{
THỰC TRANG TIÊU VIÊM CHÂN RĂNG HÀM SŨ̃A Ở BÊNHH NHÂN 5-8 TUỔI ĐẾN KHÁM TẠI VIÊ̂N ĐÀO TẠO RĂNG HÀM MĂT VÀ BÊ̂NH VIỆN RĂNG HÀM MẶT TRUNG ƯƠNG HÀ NộI NĂM 2020-2021
}

\author{
Lê Thanh Thúy ${ }^{1}$, Võ Thị Thúy Hồng ${ }^{1}$, Võ Trương Như Ngọc ${ }^{2}$
}

\section{TÓM TĂT}

Tiêu viêm chân răng sữa là một hiện tượng thường gặp trong thực hành lâm sàng của các bác sĩ răng trẻ em và có thế gây những hậu quả đáng tiếc nếu không được phát hiện, điều trị kịp thời. Nghiên cứu nhằm mục đích mô tả tỉ lệ tiêu viềm chân răng ở 1282 răng hàm sữa trên 170 trẻ từ 5 đến 8 tuổi đến khám tại Viênn đào tạo Răng Hàm Mặt và Bệnh viện Răng Hàm Mặt Trung Ương Hà Nội năm 2020-2021. Tình trạng tiều viêm chân răng hàm sữa được đánh giá thổng qua hỏi bệnh, khám lâm sàng và khảo sát trên phim panorama. Kết quả nghiên cứu cho thấy tỉ lệ tiêu viêm chân răng hàm sữa là $23,63 \%$, trong đó tỉ lệ này ở các nhóm răng sâu có tổn thương tủy răng, các răng điều trị tủy kém không làm chup, các răng trám thất bại lần lượt là 56,77\%; 23,1\%; 10,23\%. Kết luận:

${ }^{1}$ Bệnh viện Răng Hàm Mặt TƯHà Nội,

2Trường Đai hoc Y Hà Nội

Chịu trách nhiệm chính: Võ Trương Như Ngọc

Email: votruong nhu ngoc@gmail.com

Ngày nhâan bail 13/4/2021

Ngày phản biên khoa hoc: 6/5/2021

Ngày duyệt bài: 20/5/2021 nhóm các răng sâu có tổn thương tủy răng trong nghiên cứu có tỉ lệ tiêu viêm chân răng cao nhất trong khi nhóm các răng đã điều trị tủy tốt được làm chụp và nhóm răng trám thành công không thấy có hiện tượng tiêu viêm chân răng.

Tư khóa: tiêu chân răng, Viện đào tạo Răng Hàm Mặt, Bệnh viện Răng Hàm Mặt Trung ương Hà Nội.

\section{SUMMARY \\ THE REALITY OF INFLAMMATORY ROOT \\ RESORPTION IN PRIMARY MOLAR IN \\ PATIENTS 5 TO 8 YEARS OF AGE \\ EXAMINED AT SCHOOL OF ODONTO \\ STOMATOLOGY AND HANOI CENTRAL \\ NATIONAL HOSPITAL 2020-2021}

Inflammatory root resorption in primary teeth is a frequent finding in the clinical practice of pediatric dentists and can cause unfortunate consequences without being detected and treated promptly. This study aimed at describing the rate of inflammatory root resorption in 1282 primary molars of 170 children 5 to 8 years of age examined at School of Odonto Stomatology and Hanoi Central National Hospital. The status of inflammatory root resorption in primary 